\title{
An Investigation into the Electromagnetic Interactions between a Superconducting Torus and Solenoid for the Jefferson Lab $12 \mathrm{GeV}$ Accelerator Upgrade
}

\author{
R. Rajput-Ghoshal, P. K. Ghoshal, R. J. Fair, J. Hogan, D. Kashy
}

\begin{abstract}
The Jefferson Lab $12 \mathrm{GeV}$ Upgrade will allow the study of the basic properties of the building blocks of matter, how they are formed, how they interact and the forces that mediate these interactions. As part of the Jefferson Lab $12 \mathrm{GeV}$ Upgrade project, the Hall B Upgrade system, also termed CLAS12 detector, has been designed to meet the basic requirement to study the structure of nucleons and nuclei. A major focus of the Hall $B$ science program will be to determine the Generalized Parton Distributions. These studies will allow researchers, for the first time, to engage in nuclear tomography, discovering the true three-dimensional structure of the proton and the neutron. The Hall $B$ science program imposes broad requirements for measuring multiple particles over wide kinematic range with excellent resolution in momentum and angles using polarized and unpolarized targets. CLAS12 detector requires two superconducting magnets. One is a magnet system consisting of six superconducting trapezoidal racetrack-type coils assembled in a Toroidal configuration (Torus) and the second is an actively shielded solenoidal magnet (Solenoid). Both the torus and solenoid are located in close proximity to one another and are surrounded by sensitive detectors. This paper investigates the electromagnetic interactions between the two systems during normal operation as well as during various fault scenarios.
\end{abstract}

Index Terms-Torus, actively shielded, Solenoid, SSC-NbTi, Rutherford cable, conduction cooled, superconducting magnet, magnetic field, Lorentz forces, fault conditions

\section{INTRODUCTION}

A $\mathrm{S}$ part of the Jefferson Lab $12 \mathrm{GeV}$ accelerator upgrade $[1,2]$ project, Hall $\mathrm{B}$ requires two superconducting magnets. Both torus and solenoid are to be wound with Superconducting Super Collider 36-NbTi strand Rutherford cable soldered into a copper channel. The torus and solenoid are located approximately $3.5 \mathrm{~m}$ away (between magnetic centers) from each other. Fig. 1 shows the relative positions of the solenoid and torus magnets. The torus is being designed \& built by Jefferson Lab (JLab) and Fermi National Accelerator Laboratory (FNAL). The solenoid magnet is being designed and manufactured by Everson Tesla, Inc. (ETI), PA, USA. This paper investigates the electromagnetic interactions between the two magnets during normal operation as well as

Manuscript received XXXXXX Authored by Jefferson Science Associates, LLC under U.S. DOE Contract No. DE-AC05-06OR23177. The U.S. Government retains a non-exclusive, paid-up, irrevocable, world-wide license to publish or reproduce this manuscript for U.S. Government purposes.

R. Rajput-Ghoshal, P. K. Ghoshal (SMIEEE), R. J. Fair (SMIEEE), J. Hogan, D. Kashy are with the Thomas Jefferson National Accelerator Facility, Newport News, VA 23606 USA, operated by the Jefferson Science Associates for the U.S. Department of Energy Office of Science. Phone: 757-269-5992; fax: 757-269-5279; e-mail: renuka@ jlab.org. during various fault scenarios as part of rigorous Risk Assessment and Mitigation (RAM) and Failure Modes and Effects Analysis (FMEA) processes being undertaken at JLab. All the results in this paper have been obtained by modeling the magnets using VF-Cobham software (OPERA) [3].

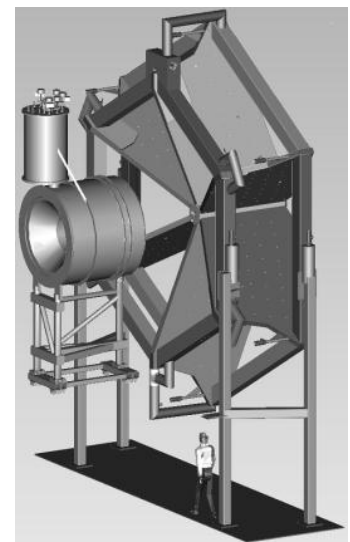

Fig. 1 Hall B CLAS12 torus and solenoid Magnet

\section{THE SUPERCONDUCTING MAGNET SYSTEMS}

The solenoid magnet consists of 5 coils -2 inner coils, 2 intermediate coils and 1 shield coil. All the coils in this magnet are electrically connected in series and cooled via a network of copper fingers. Coil 5 is the active shield and carries current in the opposite sense to the current in the other 4 coils. The other superconducting magnet is a toroidal magnet that consists of 6-independent trapezoidal racetracktype coils electrically connected in series and assembled around a central hub as shown in Fig. 1. Fig. 2 shows the asdesigned coil dimensions for solenoid and torus respectively. The coil parameters for the torus and the solenoid are given in TABLE I.
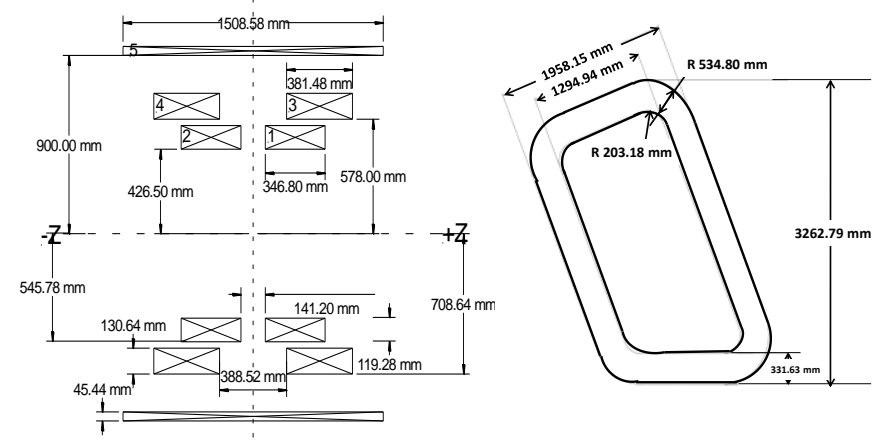

Fig. 2 Hall B Solenoid and Torus coil dimensions 
TABLE I: TORUS AND SOLENOID COIL PARAMETERS

\begin{tabular}{|l|c|c|c|}
\hline Parameter & Unit & Torus & Solenoid \\
\hline Peak operating current & $\mathrm{A}$ & 3770 & 2416 \\
\hline Coil peak field & $\mathrm{T}$ & 3.58 & 6.56 \\
\hline Number of coils & & 6 & 5 \\
\hline Total number of turns & {[]} & $(2 * 117) * 6$ & $(2 * 840)+(2 * 1012)+1392$ \\
\hline Superconducting conductor dimensions & $\mathrm{mm}$ & $2.5 \times 20$ & $2.5 \times 17$ \\
\hline NbTi strand bare diameter & $\mathrm{mm}$ & 0.648 & 0.648 \\
\hline Number of strands in the cable & & 36 & 36 \\
\hline Cu:Sc ratio (strand) & & 1.8 & 1.8 \\
\hline Critical current at 5T, 4.2 K & & \multicolumn{2}{|c|}{$11 \mathrm{kA}$} \\
\hline Total stored energy & $\mathrm{MJ}$ & 14.2 & 17.2 \\
\hline Inductance & $\mathrm{H}$ & 2 & 5.89 \\
\hline
\end{tabular}

\section{FAULT SCENARIOS AND ANALYSES}

The effect of the torus field on the solenoid magnet under normal-operating and fault conditions has been studied with regards to stray fields, forces, and torques. JLab's risk assessment of the magnet interactions requires that the following fault scenarios be investigated.

A. Solenoid alone under normal operating conditions

B. Solenoid and torus under normal operating conditions

C. Solenoid under fault conditions

D. Solenoid under fault conditions with various operating conditions of the Torus

\section{A. Solenoid alone under normal operating conditions}

Under normal operating conditions the inner and intermediate coils are attracted towards the center of the magnet with the solenoid experiencing a zero net force. The axial forces experienced by the inner and intermediate coils are high, however the pressures on the coil faces are considered to be within acceptable limits as defined by past experience of similar magnets. TABLE II and Fig. 3 indicate the magnitudes of the distributed axial and radial coil forces under normal operating conditions.

TABLE II: FORCES AND FACE PRESSURES FOR THE SOLENOID

\begin{tabular}{|c|c|c|c|c|c|}
\hline $\begin{array}{c}\text { Coil } \\
\text { Number }\end{array}$ & Fz $(\mathbf{k N})$ & $\begin{array}{c}\text { Inner radius of } \\
\text { the coil }(\mathbf{m})\end{array}$ & $\begin{array}{c}\text { Outer radius } \\
\text { of the coil }(\mathbf{m})\end{array}$ & $\begin{array}{c}\text { Area of the coil } \\
\text { face }\left(\mathbf{m}^{\mathbf{2}} \mathbf{)}\right.\end{array}$ & $\begin{array}{c}\text { Face pressure } \\
\mathbf{( M P a})\end{array}$ \\
\hline 1 & -363 & 0.4265 & 0.54578 & 0.3643 & -0.996 \\
\hline 2 & 363 & 0.4265 & 0.54578 & 0.3643 & 0.996 \\
\hline 3 & -8460 & 0.578 & 0.70864 & 0.5281 & -16.021 \\
\hline 4 & 8460 & 0.578 & 0.70864 & 0.5281 & 16.021 \\
\hline 5 & 0 & 0.9 & 0.94544 & 0.2634 & 0 \\
\hline
\end{tabular}

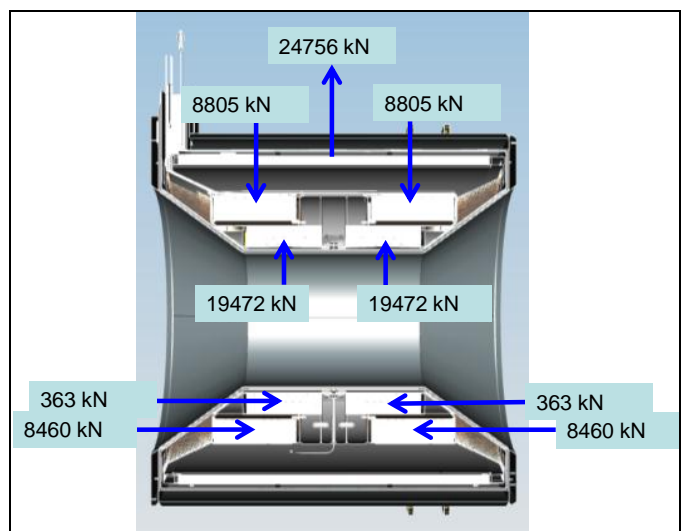

Fig. 3 The distributed coil forces under normal operating conditions
Note that there are no net axial forces on the shield coil (Coil \#5). However examination of the axial forces on one half of the shield coil indicates that the shield coil is in compression towards its center plane while the end of the coil is in tension. The forces on the intermediate coils are acting to compress each coil into the $\mathrm{C} 1-4$ bobbin (coil support former) coil slot towards the center plane of the magnet. The forces on the inner coils can also be seen to force each coil hard up against the C1-4 bobbin (i.e. towards the center plane of the magnet). This suggests that both the inner and intermediate sets of coils are well supported.

Closer examination of the axial and radial forces at the individual conductor level for each layer of the shield coil winding (a total of 16 layers) clearly shows a change from compression to tension along the axial length of the shield coil Fig. 4. In an ideal solenoidal coil, the turns are normally in axial compression and in a shield coil (with the same axial length as the main coils), turns around the coil center are in tension while turns towards the end are in compression. However, in this magnet, due to the aspect ratios of the coils and their positions relative to each other, the shield coil turns near the center and near the ends are both in compression while the turns between the center and the end are under high tension.

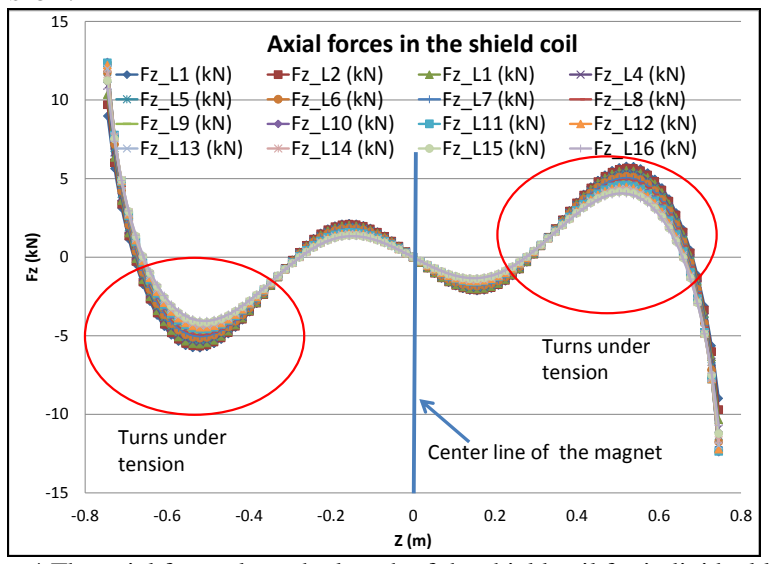

Fig. 4 The axial force along the length of the shield coil for individual layers numbered L1 to L16

\section{B. Solenoid and Torus under normal operating conditions}

The magnet configuration and stray field plot for the torus and solenoid under their normal operating conditions (solenoid at 2416A and torus at 3770A) is shown in Fig. 5. Under normal operating conditions the solenoid experiences a zero net force. The individual coils of the torus magnet experience forces in the $\mathrm{X}$ and $\mathrm{Y}$ directions, but the net force is also zero for the torus. There are no additional axial or radial forces experienced by the solenoid coils with the torus operating at full current. Table 3 summarizes the forces and torques on the solenoid coils (with and without the Torus at full operating current) while Table 4 summarizes the forces and torques on the Torus coils (with and without the solenoid at full operating current). All the torques have been calculated around the action point 0,0,0 (i.e. at the geometric center of the solenoid magnet). 

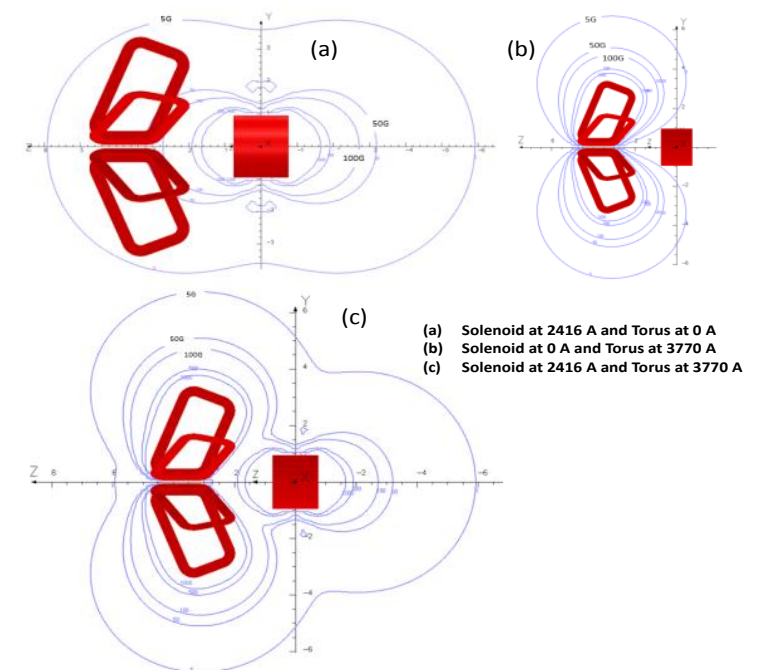

Fig. 5 Stray field plot for torus and solenoid under normal operating conditions (dim. in $\mathrm{m}$ )

The solenoid is located outside the torus $5 \mathrm{G}$ line and is therefore unlikely to have significant electromagnetic interactions with the Torus. A large proportion of the torus is located between the $5 \mathrm{G}$ and $50 \mathrm{G}$ stray field lines of the solenoid while a smaller proportion is exposed to solenoid's $100 \mathrm{G}$ line; therefore, the torus coils will be affected by the field from the solenoid.

\section{TABLE III: FORCES, TORQUES ON THE SOLENOID (WITH AND WITHOUT THE TORUS AT FIELD)}

\begin{tabular}{|c|c|c|c|c|c|c|}
\hline \multirow{2}{*}{$\begin{array}{l}\text { Coil } \\
\text { Number }\end{array}$} & \multicolumn{3}{|c|}{ Solenoid alone } & \multicolumn{3}{|c|}{$\begin{array}{l}\text { Solenoid and Torus together } \\
\text { (both at full field) }\end{array}$} \\
\hline & $\mathrm{Fx}(\mathrm{kN})$ & Fy $(\mathrm{kN})$ & $\mathrm{Fz}(\mathrm{kN})$ & $\mathrm{Fx}(\mathrm{kN})$ & Fy $(\mathrm{kN})$ & $\mathrm{Fz}(\mathrm{kN})$ \\
\hline 1 & 0 & 0 & -363 & 0 & 0 & -363 \\
\hline 2 & 0 & 0 & 363 & 0 & 0 & 363 \\
\hline 3 & 0 & 0 & -8460 & 0 & 0 & -8460 \\
\hline 4 & 0 & 0 & 8460 & 0 & 0 & 8460 \\
\hline 5 & 0 & 0 & 0 & 0 & 0 & 0 \\
\hline All Coil & 0 & 0 & 0 & 0 & 0 & 0 \\
\hline $\begin{array}{c}\text { Coil } \\
\text { Number }\end{array}$ & $\mathrm{Tx}(\mathrm{kN}-\mathrm{m})$ & Ty $(k N-m)$ & $\mathrm{Tz}(\mathrm{kN}-\mathrm{m})$ & $\mathrm{Tx}(\mathrm{kN}-\mathrm{m})$ & Ty $(\mathrm{kN}-\mathrm{m})$ & $\mathrm{Tz}(\mathrm{kN}-\mathrm{m})$ \\
\hline 1 & 0 & 0 & 0 & 0 & 0 & 0 \\
\hline 2 & 0 & 0 & 0 & 0 & 0 & 0 \\
\hline 3 & 0 & 0 & 0 & 0 & 0 & 0 \\
\hline 4 & 0 & 0 & 0 & 0 & 0 & 0 \\
\hline 5 & 0 & 0 & 0 & 0 & 0 & 0 \\
\hline All Coil & 0 & 0 & 0 & 0 & 0 & 0 \\
\hline
\end{tabular}

TABLE IV: FORCES, TORQUES ON THE TORUS (WITH AND WITHOUT THE SOLENOID AT FIELD)

\begin{tabular}{|c|c|c|c|c|c|c|}
\hline \multirow{2}{*}{$\begin{array}{l}\text { Coil } \\
\text { Number }\end{array}$} & \multicolumn{3}{|c|}{ Torus alone } & \multicolumn{3}{|c|}{$\begin{array}{l}\text { Solenoid and Torus together } \\
\text { (Both at full field) }\end{array}$} \\
\hline & $\mathrm{F} \times(\mathrm{kN})$ & Fy $(\mathrm{kN})$ & $\mathrm{Fz}(\mathrm{kN})$ & $\mathrm{Fx}(\mathrm{kN})$ & Fy $(\mathrm{kN})$ & $\mathrm{Fz}(\mathrm{kN})$ \\
\hline $\mathrm{T} 1$ & 0 & 1430 & 0 & 4 & 1430 & 0 \\
\hline $\mathrm{T} 2$ & -1239 & 715 & 0 & -1236 & 719 & 0 \\
\hline T3 & -1239 & -715 & 0 & -1241 & -711 & 0 \\
\hline T4 & 0 & -1430 & 0 & -4 & -1430 & 0 \\
\hline T5 & 1239 & -715 & 0 & 1236 & -719 & 0 \\
\hline T6 & 1239 & 715 & 0 & 1241 & 711 & 0 \\
\hline All Coils & 0 & 0 & 0 & 0 & 0 & 0 \\
\hline $\begin{array}{c}\text { Coil } \\
\text { Number }\end{array}$ & $\mathrm{T} \times(\mathrm{kN}-\mathrm{m})$ & Ty $(\mathrm{kN}-\mathrm{m})$ & $\mathrm{Tz}(\mathrm{kN}-\mathrm{m})$ & $\mathrm{Tx}(\mathrm{kN}-\mathrm{m})$ & Ty $(k N-m)$ & $\mathrm{Tz}(\mathrm{kN}-\mathrm{m})$ \\
\hline $\mathrm{T} 1$ & -5212 & 0 & 0 & -5212 & 9 & 0 \\
\hline $\mathrm{T2}$ & -2606 & -4514 & 0 & -2614 & -4510 & 0 \\
\hline T3 & 2606 & -4514 & 0 & 2599 & -4518 & 0 \\
\hline T4 & 5212 & 0 & 0 & 5212 & -9 & 0 \\
\hline T5 & 2606 & 4514 & 0 & 2614 & 4510 & 0 \\
\hline T6 & -2606 & 4514 & 0 & -2599 & 4518 & 0 \\
\hline All Coils & 0 & 0 & 0 & 0 & 0 & 0 \\
\hline
\end{tabular}

It is evident from TABLE III and TABLE IV that the torus does not exert any additional axial or radial forces or torques on the solenoid. The forces and torques for the individual coils of the torus magnet change by less than $0.5 \%$ when the solenoid is at full field, but the net force remains unchanged for normal operating conditions.

\section{Solenoid under fault conditions}

The RAM and FMEA processes have also necessitated the investigation of a number of fault conditions primarily related to electrical shorts in the solenoid coils. Two scenarios have been investigated:

(a) A single short of extremely low resistance between two layers within a coil (i.e. equivalent to losing two layers) - The probability of this occurrence is low and can be mitigated by identifying and addressing vulnerable regions within the coil assembly where this event could occur - for example the lead entry and exit points, insulated conductors being abraded during the winding process, etc. The effect of losing 2 innermost or outermost layers within the inner, intermediate or shield coils have been simulated and forces calculated for these fault conditions.

TABLE V: AXIAL FORCES ON THE COILS DUE TO THE LOSS OF 2 LAYERS IN A COIL

\begin{tabular}{|c|c|c|c|c|c|c|c|}
\hline & \multicolumn{7}{|c|}{ Axial Force Fz $(\mathrm{kN})$} \\
\hline Coil \#\# & $\begin{array}{c}\text { Normal } \\
\text { operation }\end{array}$ & $\begin{array}{c}\text { One inner } \\
\text { coil has lost } \\
2 \text { innermost } \\
\text { layers }\end{array}$ & $\begin{array}{c}\text { One inner } \\
\text { coil has lost } \\
2 \\
\text { outermost } \\
\text { layers }\end{array}$ & $\begin{array}{c}\text { One } \\
\text { intermediate } \\
\text { coil has lost } \\
2 \text { innermost } \\
\text { layers }\end{array}$ & $\begin{array}{c}\text { One } \\
\text { intermediate } \\
\text { coil has lost 2 } \\
\text { outermost } \\
\text { layers }\end{array}$ & $\begin{array}{c}\text { innermost } \\
\text { layers of } \\
\text { shield coils } \\
\text { are lost }\end{array}$ & $\begin{array}{c}\text { 2 outermost } \\
\text { layers of shield } \\
\text { coils are lost }\end{array}$ \\
\hline 1 & -363 & -290 & -427 & -660 & -521 & -466 & -462 \\
\hline 2 & 363 & 212 & 180 & 235 & 235 & 466 & 462 \\
\hline 3 & -8460 & -8304 & -8101 & -8007 & -8169 & -8831 & -8818 \\
\hline 4 & 8460 & 8350 & 8299 & 8330 & 8303 & 8831 & 8818 \\
\hline 5 & 0 & 31 & 50 & 102 & 152 & 0 & 0 \\
\hline
\end{tabular}

TABLE $\mathrm{V}$ summarizes the axial forces on all the solenoid coils under this fault condition. Losing 2 inner layers in intermediate coil has the maximum effect and is the subject of detailed structural analysis. Changes in the radial forces are not significant and are not shown here.

(b) A double short to ground of extremely low resistance in the magnet (i.e. equivalent to losing the whole coil) - The probability of this occurrence is very low and can be detected during ramping of the magnet by monitoring the installed load cells. However, the penalty on the magnet performance and mechanical structure is high and the magnet is unusable.

The effects of losing one inner, intermediate or shield coil are simulated with the axial and radial forces summarized in TABLE VI.

\section{TABLE VI: AXIAL AND RADIAL FORCES ON THE COILS DUE TO THE LOSS OF A WHOLE COIL}

\begin{tabular}{|c|c|c|c|c|c|c|c|c|}
\hline & \multicolumn{4}{|c|}{ Axial Force $\mathrm{Fz}(\mathrm{kN})$} & \multicolumn{4}{c|}{ Radial Force Fr (kN) } \\
\hline Coil \# & $\begin{array}{c}\text { Normal } \\
\text { operation }\end{array}$ & $\begin{array}{c}\text { One } \\
\text { Inner coil } \\
\text { off }\end{array}$ & $\begin{array}{c}\text { One } \\
\text { intermediate } \\
\text { coil off }\end{array}$ & $\begin{array}{c}\text { Shield } \\
\text { coil off }\end{array}$ & $\begin{array}{c}\text { Normal } \\
\text { operation }\end{array}$ & $\begin{array}{c}\text { One } \\
\text { Inner } \\
\text { coil Off }\end{array}$ & $\begin{array}{c}\text { One } \\
\text { intermediate } \\
\text { coil off }\end{array}$ & $\begin{array}{c}\text { Shield } \\
\text { coil off }\end{array}$ \\
\hline 1 & -363 & 0 & -5507 & -1201 & 19691 & 0 & 1836 & 31036 \\
\hline 2 & 363 & -3119 & -2515 & 1201 & 19691 & 17073 & 15835 & 31036 \\
\hline 3 & -8460 & -3312 & 0 & -11369 & -8930 & -3157 & 0 & 9183 \\
\hline 4 & 8460 & 5587 & 5115 & 11369 & -8930 & -10388 & -11970 & 9183 \\
\hline 5 & 0 & 843 & 2908 & 0 & 24963 & 23216 & 21323 & 0 \\
\hline
\end{tabular}

A detailed study on the effect on the magnetic field homogeneity of the solenoid (specification $<100$ ppm peak-topeak over a cylinder of $25 \mathrm{~mm}$ diameter x $40 \mathrm{~mm}$ long) has shown that most of the fault conditions considered here lead to a very inhomogeneous field, lower central field and large stray fields on the detector locations. The "one inner coil off" case results in the lowest central field $(3.13 \mathrm{~T})$, and highest inhomogeneity in the field (51943 ppm). The maximum stray field at the detector location is for the shield off case as shown in TABLE VII. 
TABLE VII: STRAY FIELD AT THE DETECTOR LOCATIONS

\begin{tabular}{|c|c|c|c|c|c|c|c|}
\hline \multicolumn{2}{|c|}{ Detector position } & \multicolumn{7}{|c|}{ Field in G } \\
\hline $\begin{array}{c}\text { Radial } \\
(\mathrm{mm})\end{array}$ & Axial $(\mathrm{mm})$ & Spec. & $\begin{array}{c}\text { Design } \\
\text { Value }\end{array}$ & $\begin{array}{c}2 \text { Inner layer of } \\
\text { inner coil off }\end{array}$ & $\begin{array}{c}\text { 2 outer layers } \\
\text { of shield coil } \\
\text { off }\end{array}$ & $\begin{array}{c}\text { Intermediate } \\
\text { coil off for 5 T } \\
\text { central field }\end{array}$ & $\begin{array}{c}\text { Shield off for 5T } \\
\text { central field }\end{array}$ \\
\hline 1947 & 708 & $<35$ & 15 & 17 & $\mathbf{1 5 3}$ & $\mathbf{6 8 5}$ & $\mathbf{8 7 2}$ \\
\hline 1902 & 425 & $<35$ & 6 & 9 & $\mathbf{1 6 7}$ & $\mathbf{7 4 8}$ & $\mathbf{9 4 2}$ \\
\hline 1789 & 163 & $<35$ & 4 & 7 & $\mathbf{2 0 1}$ & $\mathbf{9 0 8}$ & $\mathbf{1 1 0 9}$ \\
\hline 1613 & -52 & $<35$ & 11 & 5 & $\mathbf{2 7 0}$ & $\mathbf{1 2 2 7}$ & $\mathbf{1 4 6 1}$ \\
\hline 526 & -1450 & $<1200$ & 1134 & 1117 & $\mathbf{1 6 1 4}$ & 832 & $\mathbf{3 7 6 7}$ \\
\hline 1145 & 574 & $<1200$ & 612 & 631 & $\mathbf{7 6 7}$ & $\mathbf{4 8 5 8}$ & $\mathbf{4 0 0 3}$ \\
\hline
\end{tabular}

D. Solenoid under fault conditions with various operating conditions of the torus

The fault conditions studied for the torus magnet alone are electrical shorts and mechanical coil misalignment. Under severe mechanical or electrical faults the torus magnet will fail. However there are a few fault conditions under which the torus can still be operated safely. The effects on the solenoid (under solenoid normal and fault conditions) of 2 such fault conditions in the torus are presented here.

Fault \#1: One of the six torus coils is operating at $90 \%$ of full operating current; Fault \#2: One coil of the torus is displaced by $5 \mathrm{~mm}$ away from the hub (beam axis) and also tilted by 1 deg (the worst case). A brief summary of forces and torques calculated for the solenoid and torus magnets are presented in TABLE VIII \& TABLE IX. TABLE X summarizes the forces and torques resulting from a combined fault in the solenoid and Fault \#1 and \#2 in the torus.

TABLE VIII: TYPICAL FORCE AND TORQUES FOR SOLENOID \& TORUS COILS FOR FAULT \# 1

\begin{tabular}{|c|c|c|c|c|c|c|}
\hline \multirow{2}{*}{ Coil } & \multicolumn{6}{|c|}{ Coil 2 of Torus has $90 \%$ current } \\
\hline & $\mathrm{Fx}(\mathrm{kN})$ & $\mathrm{Fy}(\mathrm{kN})$ & $\mathrm{Fz}(\mathrm{kN})$ & $\mathrm{T} \times(\mathrm{kN}-\mathrm{m})$ & $\operatorname{Ty}(\mathrm{kN}-\mathrm{m})$ & $\mathrm{Tz}(\mathrm{kN}-\mathrm{m})$ \\
\hline \multirow{5}{*}{ Solenoid } & 1 & 1 & -363 & -1 & 1 & 0 \\
\hline & 0 & 1 & 363 & -1 & 0 & 0 \\
\hline & 1 & 2 & -8460 & -3 & 2 & 0 \\
\hline & 1 & 1 & 8460 & -1 & 1 & 0 \\
\hline & -3 & -4 & 0 & 6 & -3 & 0 \\
\hline $\begin{array}{c}\text { All Solenoid } \\
\text { coils }\end{array}$ & 0 & o & 0 & -1 & 0 & 0 \\
\hline $\mathrm{T} 1$ & -64 & 1391 & 0 & -5069 & -239 & -54 \\
\hline $\mathrm{T} 2$ & -1113 & 647 & 0 & -2352 & -4059 & 0 \\
\hline T3 & -1241 & -633 & 0 & 2312 & -4518 & 54 \\
\hline T4 & -18 & -1407 & 0 & 5128 & -57 & 11 \\
\hline T5 & 1221 & -710 & 0 & 2580 & 4452 & 0 \\
\hline T6 & 1214 & 711 & 0 & -2599 & 4421 & -11 \\
\hline $\begin{array}{l}\text { All Torus } \\
\text { Coils }\end{array}$ & 63 & -1392 & 0 & 5071 & 238 & 54 \\
\hline
\end{tabular}

TABLE IX: TYPICAL OF FORCE AND TORQUES FOR SOLENOID \& TORUS COILS FOR FAULT \#2

\begin{tabular}{|c|c|c|c|c|c|c|}
\hline \multirow[b]{2}{*}{ Coil } & \multicolumn{6}{|c|}{ Torus with T1-5mm T2 $1 \mathrm{deg}$ towards T1 } \\
\hline & $\mathrm{Fx}(\mathrm{kN})$ & $\mathrm{Fy}(\mathrm{kN})$ & $\mathrm{Fz}(\mathrm{kN})$ & $\mathrm{T} \times(\mathrm{kN}-\mathrm{m})$ & Ty $(\mathrm{kN}-\mathrm{m})$ & $\mathrm{Tz}(\mathrm{kN}-\mathrm{m})$ \\
\hline \multirow{5}{*}{ Solenoid } & 0 & 0 & -363 & 0 & 0 & 0 \\
\hline & 0 & 0 & 363 & 0 & 0 & 0 \\
\hline & 0 & 0 & -8460 & 0 & 1 & 0 \\
\hline & 0 & 0 & 8460 & 0 & 0 & 0 \\
\hline & -1 & 0 & 0 & 1 & -1 & 0 \\
\hline $\begin{array}{c}\text { All Solenoid } \\
\text { coils }\end{array}$ & 0 & 0 & 0 & 0 & 0 & 0 \\
\hline T1 & 1 & 1437 & -1 & -5236 & -5 & -3 \\
\hline $\mathrm{T} 2$ & -1251 & 705 & -1 & -2564 & -4563 & -16 \\
\hline T3 & -1268 & -698 & -1 & 2552 & -4616 & 41 \\
\hline T4 & 16 & -1437 & 1 & 5239 & 65 & -17 \\
\hline T5 & 1254 & $\begin{array}{l}-723 \\
\end{array}$ & -1 & 2630 & 4574 & -4 \\
\hline T6 & 1248 & 718 & -1 & -2621 & 4544 & -2 \\
\hline $\begin{array}{l}\text { All Torus } \\
\text { Coils }\end{array}$ & 0 & 0 & -3 & 0 & 0 & 0 \\
\hline
\end{tabular}

A detailed mechanical analysis has been carried out for the selected fault conditions for the solenoid [4]. For the cases that suggest an unusable magnet (i.e. the magnet cannot be energized), the stresses in the coils have not been studied in detail. However the stresses in the coil support structures have been investigated. The three cases are described as follows: Case \#1: one of the intermediate coils has lost 2 innermost layers; Case \#2: one intermediate coil is off; Case \#3: one of the torus coils is at $90 \%$ current and one of the intermediate coils has lost 2 innermost layers.
Analysis results show that all cases could result in a mechanical failure of the stainless steel bobbin that supports the inner and intermediate coils. Case \#2 indicates high tensile forces in the axial restraints (z-stops), so that these structural links could fail.

TABLE X: TYPICAL FORCES AND TORQUES UNDER A FAULT CONDITION IN THE SOLENOID IN CONJUNCTION WITH FAULTS \#1 FOR TORUS

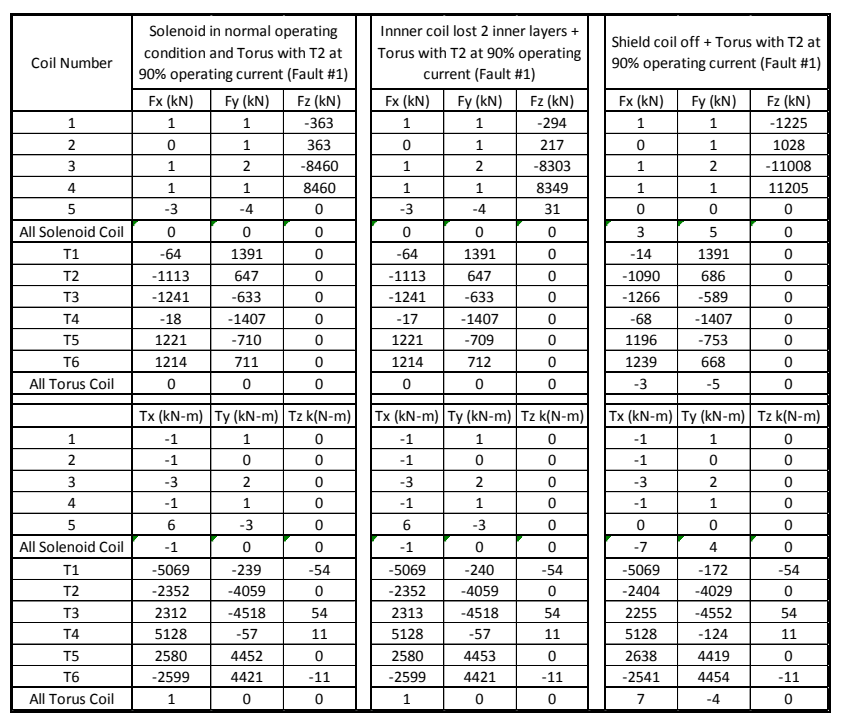

\section{CONCLUSIONS}

The following conclusions can be drawn from the above studies:

i. The shield coil is in overall axial tension, the potted conductor and epoxy in tension could be a cause of potential magnet failure. Further structural analysis is being carried out to investigate this.

ii. The torus does not exert any additional axial or radial forces or torques on the solenoid magnet. The forces and torques for the individual coils of the torus magnet change by less than $0.5 \%$ in the presence of the solenoid and net forces remain unchanged.

iii. The torus magnet, under normal operating conditions, does not exert any force or torque on the solenoid magnet. However, under certain fault conditions, the torus does exert very small torques on the solenoid magnet.

iv. The worst but very improbable case (maximum torque) is for the torus with one of torus coils at $90 \%$ of full operating current (Fault \#1) and no active shield in the solenoid, as a mitigation action solenoid will be tested independent of torus magnet.

\section{ACKNOWLEDGMENT}

This work was supported in part by the U.S. Department of Energy under U.S. DOE Contract No. DE-AC05-06OR23177. The authors would like to thank the team at JLab and Hall_B solenoid vendor Everson Tesla Inc. for their valued insights and shared experiences. 


\section{REFERENCES}

[1] C. H. Rode, "Jefferson lab $12 \mathrm{GeV}$ CEBAF upgrade," Trans. of Cryogenic Eng. Conference, CEC: Advances in Cryogenic Engineering, vol. 1218,2010 , pp. $26-33$

[2] R. J. Fair, G. L. Young, "Superconducting Magnets for the $12 \mathrm{GeV}$ Upgrade at Jefferson Laboratory", IEEE Trans. on Appl. Supercond., ASC 2014

[3] Vector field software tool for Electromagnetic modeling http://www.cobham.com/

[4] Gary Cheng, "JLAB Hall B solenoid Coil Structural Analysis Final Report" and "JLAB Hall B Solenoid Fault Condition Analysis Report 1_25Mar2014", JLAB internal report June 2014 